\title{
Survival in haemolytic disease of newborn due to Rh-isoimmunisation: an unusual presentatio
}

\begin{abstract}
Immune mediated haemolytic disease of newborn (HDN) refers to a specific category of haemolytic anaemia that results from transplacental passage of IgG antibodies from a pre-sensitized mother to her fetus in utero. This occurs due to blood group incompatibility between the mother and the fetus. The clinical presentation covers a wide spectrum spanning from infants born with only mild haemolysis to those having severe anaemia and hydrops. We describe a unique case of a successful live birth of $\mathrm{Rh}$ D-positive female child in Rh D-negative mother, after four consecutive pregnancies affected by $\mathrm{Rh}$ isoimmunisation, leading to intrauterine death of the four fetuses. Although the neonate was affected with moderate HDN, she responded to intensive management by exchange transfusion and phototherapy, and was finally stabilized by the 7 th post natal day.
\end{abstract}

Volume 2 Issue 4 - 2017

\section{Kafil Akhtar, Prasenjit Sen Ray, Zeba Z Rab,} Rana K Sherwani

Department of Pathology, Jawaharlal Nehru Medical College, India

Correspondence: Kafil Akhtar, Department of Pathology, Jawaharlal Nehru Medical College, Aligarh Muslim University, India, Email kafilakhtar@gmail.com

Received: May 05, 2017 | Published: June 20, 2017

Keywords: isoimmunisation, hemolysis, rh-d incompatibility, live newborn

\section{Introduction}

Haemolytic disease of newborn (HDN) is a condition of premature destruction of red blood cells (RBC) of foetus in uteri and newborns during early neonatal period. This can be immune or non-immune mediated. The commonest underlying reason of the former is transplacental passage of $\operatorname{IgG}$ Antibodies produced by sensitized mother and directed against Rhesus, $\mathrm{ABO}$ or other antigens on foetal RBCs. Of these, Isoimmunisation with Rh-D antigen causes the most severe form of HDN. A history of previously affected foetus or infant in Rh-negative mother predicts a high chance of similar or greater morbidity in future pregnancies with Rh-positive foetus. ${ }^{1}$

This report describes the case of successful live birth of an $R h$ D-positive neonate in an Rh D-negative mother, after her previous four consecutive pregnancies were affected by $\mathrm{Rh}$ isoimmunisation and ended in fatal consequences. Although this newborn suffered from HDN after birth, strikingly she responded to active management and was stabilized by eighth postnatal day. Through this report the authors intend to showcase an atypical presentation of Rh-HDN.

\section{Case summary}

A 28 years old Indian female with 36weeks amenorrhoea and in labour was referred to our tertiary care hospital from the local primary health centre. The obstetric history revealed her to be eighth graivida. Her first three children were alive, healthy and born of normal vaginal delivery. The fourth child had jaundice at birth and died on the second day. There after she conceived thrice, all of which culminated in still births. Unfortunately, as this lady came from a poor socio-economic status and rural background, she did not receive proper antenatal check up in any of her pregnancies.

Laboratory workup showed her blood group to be $\mathrm{O}$ Rh-negative with indirect Antiglobulin test positive by gel card technique. (Figure 1) No satisfactory history of prior anti-D immune prophylaxis could be obtained in the mother. The father's blood group was $\mathrm{O}$ Rh-positive. This history coupled with laboratory findings led to a suspicion of pregnancy with Rh isoimmunisation. The suspicion was further augmented when the blood group of the third live child was detected to be O Rh-positive. Since the patient was already in labour, closely monitored vaginal delivery was conducted and a live female child was born. The baby was active after birth but appeared mildly pale and icteric. Mild hepatosplenomegaly was present although oedema was absent. Investigations from cord blood revealed that the newborn's blood group was O Rh-positive, Haemoglobin 122gm/L, total serum bilirubin $87.2 \mu \mathrm{mol} / \mathrm{L}$ (indirect fraction $70.1 \mu \mathrm{mol} / \mathrm{L}$ ) and direct antiglobulin test positive by gel card technique Figure 1 . The newborn was transferred to neonatal intensive care unit (NICU) for further management.

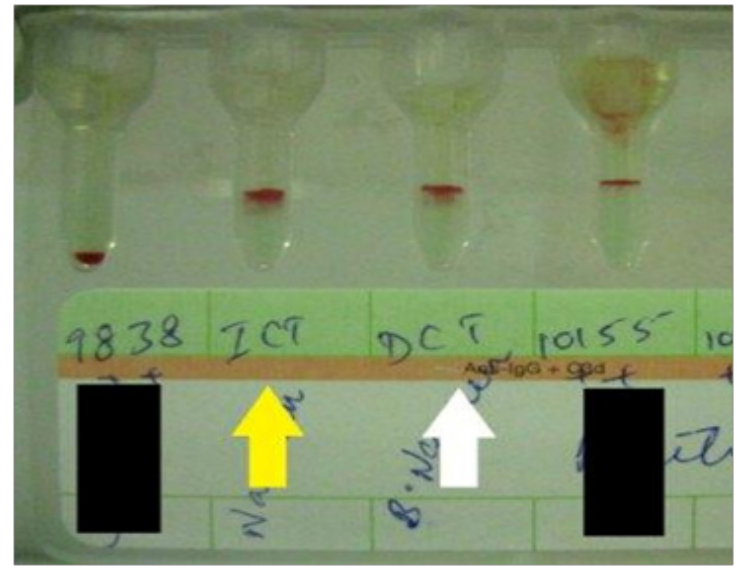

Figure I Gel card showing positive indirect antiglobulin test in mother (yellow arrow) and positive direct antiglobulin test in the newborn (white arrow).

Subsequently, there was sharp rise in serum bilirubin to $261.6 \mu \mathrm{mol} / \mathrm{L}$ (indirect fraction $234.2 \mu \mathrm{mol} / \mathrm{L}$ ) and drop in haemoglobin to $65 \mathrm{gm} / \mathrm{L}$ by second postnatal day, despite trial of phototherapy. Peripheral smear showed Anisopoikilocytosis of red cells, abundant polychromatic cells and erythroblastosis (74 nucleated-RBCs/100WBCs) Figure 2.

Total leucocyte count was $23.24 \times 10^{9} / \mathrm{L}$ with neutrophilia (polymorphs- $88 \%$, lymphocytes- $12 \%$ ), platelet count $530 \times 10 / \mathrm{L}$ and reticulocyte count $19.4 \%$. 


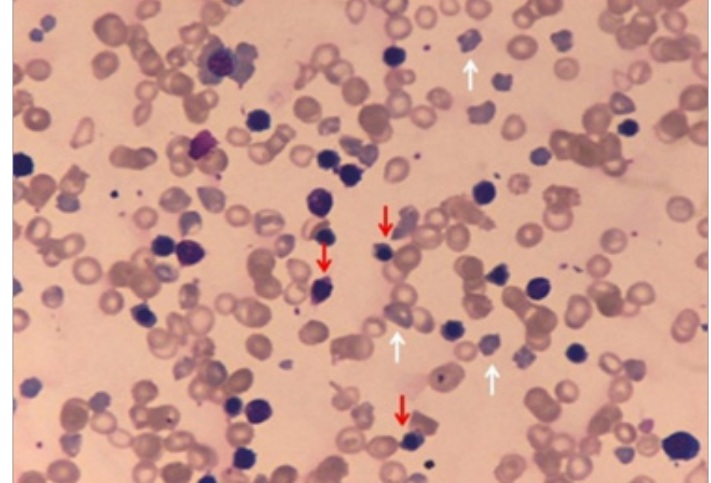

Figure 2 Microphotograph of peripheral blood smear of the newborn showing anisopoikilocytosis of red cells with polychromatic cells (white arrows) and numerous nucleated RBCs (red arrows) - erythroblastic blood picture (Leishman stain, 400x).

In view of severe anaemia and impending kernicterus, exchange transfusion with fresh $\mathrm{O}$ Rh-negative whole blood compatible with mother's serum was undertaken. After 4 episodes of exchange transfusion, conducted over next 5days, the newborn's condition showed gradual signs of improvement. Interestingly, the baby tolerated these procedures well and by seventh postnatal day, her haemoglobin rose to $128 \mathrm{gm} / \mathrm{L}$ while serum bilirubin decreased to $53.0 \mu \mathrm{mol} / \mathrm{L}$. Phototherapy and supportive medical care were continued all along. The baby was finally shifted out of NICU on eighth postnatal day in stable condition. In follow up, the baby required packed red cell transfusion twice at the age of 2 months and 4months respectively. Presently the baby is in regular check up and is doing well.

\section{Discussion}

In humans, Rh antigenic determinants are inherited from each parent and direct the production of several blood group factors (C, c, D, d, E, e). Of these, Rh-D is the most important RBC antigen encountered in transfusion medicine, because it is the most immunogenic amongst all blood group antigens. In HDN due to Rh incompatibility, D antigen is responsible in about $90 \%$ cases. Rarely c, C and E antigens are implicated. The incidence of HDN due to D antigen is approximately thrice more common among Caucasians than blacks. ${ }^{1,2}$

Formation of anti-D antibody in Rh-negative individuals is always secondary to exposure to Rh-positive RBCs. In females, this occurs either through mismatched blood transfusion, or more commonly, when $\mathrm{Rh}$ D-positive foetal RBCs enter maternal circulation during pregnancy, abortion or delivery. In the latter scenario, foetus inherits $\mathrm{D}$ antigen from its $\mathrm{Rh} \mathrm{D}$-positive father. Even $1 \mathrm{ml}$ of $\mathrm{Rh} \mathrm{D}$-positive red cells are enough to induce primary immune response. ${ }^{1,3}$

In subsequent pregnancies with Rh-positive foetus, preformed anti-D antibodies (IgG type) from the sensitized mother are transported across the placenta into foetal circulation causing extra vascular haemolysis of foetal RBCs and anaemia. Mildly suffering neonates ( $\sim 15 \%$ cases) have only laboratory evidence of haemolysis without symptomatic anaemia. ${ }^{1,3}$ On the contrary, in severely affected foetus, compensatory erythropoiesis in liver and spleen leads to hepato-splenomegaly and the characteristic erythroblastic peripheral blood picture. When anaemia becomes more severe, cardiac failure with circulatory collapse and anasarca ensue, resulting in the condition clinically described as hydrops foetalis the most ominous form of HDN. Around $20-25 \%$ of $\mathrm{Rh}$ isoimmunisation cases meet this consequence. ${ }^{3,4}$
The other important manifestation of HDN is jaundice, often detectable from the first day of life. Due to rapid haemolysis, there is increase in fetal unconjugated bilirubin. In utero, it is cleared off by placenta and foetus remains essentially unaffected. Following delivery, this protective mechanism is withdrawn causing a rapid surge in serum bilirubin. In untreated cases, the newborn's liver fails to conjugate this huge load and when serum level exceeds $340 \mu \mathrm{mol} / \mathrm{L}$ (in term infants), unconjugated bilirubin gets deposited in brain leading to potential neurological damage (kernicterus). ${ }^{2,3}$ However, reports exist in literature where only anaemia in the absence of jaundice has been the clinical presentation of Rh-HDN. ${ }^{4}$ Other potentially lethal co-morbidities of HDN that need clinicians' attention are hypoxia, acidosis and hypoglycaemia. ${ }^{1-3}$

With the introduction of time bound antenatal checkups and routine postnatal prophylactic anti-D immunoglobulin administration to all Rh-negative mothers, the incidence of Rh-HDN has decreased dramatically in developed countries. ${ }^{5,6}$ Observed a decrease in the rate of anti-D positivity in women of reproductive age to $2.6 / 1000$ samples as compared to 43.3/1000 samples reported by. ${ }^{5,6}$ According the trend of having smaller families and improved perinatal care also contributed significantly towards this decline in morbidity and mortality. ${ }^{7}$

In a contrasting study, however, found that the scenario has not changed so much in developing nations like India where large numbers of pregnancies still remain unbooked and a major proportion of deliveries continue to take place at home. ${ }^{8}$ Mothers from rural areas are frequently unaware of their blood group and their Rh-negative status is only discovered in second or later pregnancies, when the baby presents with severe hyperbilirubinemia and anaemia to referral centres. Therefore, Rh-HDN continues to remain an important cause of neonatal morbidity and mortality in our scenario, although exact data in this regard is lacking. ${ }^{\text {? }}$

In our own case, the mother is presumed to be sensitised to Rh-D antigen in third pregnancy, following which next four babies met the ill fate of fatal HDN. The severity of Rh-HDN is said to worsen with successive pregnancies. However, available literature also states that ability of Rh-negative women to generate antibodies can show considerable variation with some producing low titres, even after adequate antigenic challenge. ${ }^{2}$ This fact may probably explain why the present newborn survived despite of being affected by HDN.

\section{Conclusion}

With this case, we intend to highlight an atypical presentation of RhHDN and emphasize on the fact that this potentially lethal condition is preventable by timely anti-D immunoglobulin administration to all $\mathrm{Rh}$-negative mothers supplemented with stringent antenatal and perinatal care.

\section{Acknowledgements}

None.

\section{Conflict of interest}

Authors declare there in no conflicts in publishing the article.

\section{References}

1. Sapp MV, Bussel JB. Immune haemolytic anaemias. In: Lilleyman JS, editor. Paediatric Hematology, London. 2nd ed. UK: Churchill Livingstone; 2010. p. 214-216. 
2. Stoll BJ. Blood disorders. In: Kliegman RM, editors. Nelson Textbook of Pediatrics. 18th ed. Philadelphia: Saunders Elsevier; 2012. p. 753-756.

3. Zipursky A, Pollock J, Neelands P, et al. The transplacental passage of foetal red blood cells and the pathogenesis of $\mathrm{Rh}$ immunisation during pregnancy. Lancet. 1913;2(7306):489-493.

4. Louis D, Oberoi S, Sundaram V, et al. Isolated early onset anemia after $\mathrm{Rh}$ isoimmunisation : a unique presentation in 3 neonates. $J$ Pediatr Hematol Oncol. 2010;32(6):e230-e232

5. Geifman-Holtzman O, Wojtowycz M, Kosmas E, et al. Female alloimmunization with antibodies known to cause haemolytic disease. Obstet Gynecol. 2007;89(2):272-275.
6. Polsky M, Wojtowycz M, Kosmas E, et al. Female alloimmunization with antibodies known to cause haemolytic disease. Obstet Gynecol. 2009;99(6):277-281.

7. Joseph KS, Kramer MS. The decline in Rh haemolytic disease: Should Rh prophylaxis get all the credit? Am J Public Health. 1998;88(2):209-215.

8. Gupta V, Bhatia B, Kumar A. Changing face of haemolytic anaemia in newborn. J Neonatol. 2011;25(2):76-81. 